\title{
Avaliação de áreas elegíveis à implantação de projetos de MDL florestais na bacia do Rio Pardo, em Minas Gerais
}

\author{
Gesiane Simara BARBOSA ${ }^{1}$, Ronaldo Medeiros dos SANTOS ${ }^{1 *}$, Vinícius Orlandi Barbosa LIMA ${ }^{1}$, \\ Marcelo Rossi VICENTE1, Tábata Ritchielle Mendes MARTINS ${ }^{1}$
}

${ }^{1}$ Instituto Federal de Educação, Ciência e Tecnologia do Norte de Minas Gerais, Salinas, MG, Brasil.

*E-mail: ronaldo.medeiros@ifnmg.edu.br

(Orcid: 0000-0002-5424-4209; 0000-0003-1717-5467; 0000-0003-4252-2942; 0000-0003-2516-5656; 0000-0003-4593-1055)

Recebido em 24/09/2020; Aceito em 03/02/2021; Publicado em 17/02/2021.

\begin{abstract}
RESUMO: No Protocolo de Quito, ratificado em 1997, foi proposto um instrumento de mitigação climática - o Mecanismo de Desenvolvimento Limpo (MDL) - em que países desenvolvidos podem cumprir suas metas de redução de emissões financiando projetos florestais em países em desenvolvimento. $O$ ponto de partida consiste na avaliação do potencial de sequestro de $\mathrm{CO}_{2}$ de áreas elegíveis. Nesse sentido, o objetivo deste trabalho foi avaliar o potencial de sequestro $\mathrm{CO}_{2}$ e de geração de créditos de carbono na bacia do Rio Pardo, MG, a partir de projetos de MDL florestais. A metodologia consistiu no mapeamento das áreas elegíveis à implantação de projetos, via análise multitemporal de imagens orbitais, e na simulação de cenários de restauração florestal e reflorestamento com eucalipto. Para restauração florestal, o potencial de sequestro de $\mathrm{CO}_{2}$ foi de, aproximadamente, $10.215 .818 \mathrm{Mg}$, em 20 anos, podendo gerar mais de US $\$ 102$ milhões em créditos de carbono. Para reflorestamento, o potencial de sequestro de $\mathrm{CO}_{2}$ foi de, aproximadamente, $12.000 .000 \mathrm{Mg}$, em seis anos, e geraria cerca de US $\$ 120.000 .000$. Um cenário misto foi considerado o ideal para a bacia e a metodologia adotada é viável para avaliação em caráter prospectivo, podendo ser consolidada com a utilização de parâmetros locais de biomassa.
\end{abstract}

Palavras-chave: mudanças climáticas; florestas; sequestro de carbono; geoprocessamento.

\section{Evaluation of eligible areas for forest CDM projects implementation in the Pardo River basin, in Minas Gerais, Brazil}

\begin{abstract}
An instrument for climate changes mitigation was proposed in Kyoto Protocol, ratified in 1997 - the Clean Development Mechanism - CDM - through which developed countries can meet their emission reduction goals by forestry projects financing in developing countries. For this, the starting point is to assess the $\mathrm{CO}_{2}$ sequestration potential of the eligible areas. In this sense, the objective of the present work was to evaluate the $\mathrm{CO}_{2}$ sequestration potential and carbon credits generation through forestry CDM projects in the Pardo river basin, Minas Gerais state. The methodology consisted of mapping the eligible and suitable areas for projects implementation, through orbital images multitemporal analysis, and the simulation of forest restoration and reforestation scenarios with eucalyptus species. For forest restoration projects, the $\mathrm{CO}_{2}$ sequestration potential is about $10,215,818 \mathrm{Mg}$, in 20 years, which could generate more than US $\$ 102,000,000$ in carbon credits. For reforestation, the $\mathrm{CO}_{2}$ sequestration potential is about $12,000,000 \mathrm{Mg}$ in six years, and would generate about US $\$ 120,000,000$. A mixed scenario, with projects in both modalities, was considered ideal for the basin and the proposed methodology is feasible for prospective evaluation, and can be consolidated using local biomass parameters.
\end{abstract}

Keywords: climatic change; forests; carbon sequestration; geoprocessing.

\section{INTRODUÇÃO}

Desde 1988, quando se falou pela primeira vez, a nível mundial, na Assembleia Geral das Nações Unidas ocorrida no referido ano, sobre mudanças climáticas como uma questão comum à humanidade, esforços globais têm sido empreendidos no sentido de discutir, de compreender e de enfrentar os impactos advindos do referido processo, que, segundo Alvarenga; Carmo (2006), compreendem a ocorrência de fenômenos extremos, como a elevação do nível do mar, mudanças no regime de chuvas, perda da biodiversidade, êxodo humano, quebra na produção de alimentos e aumento global da pobreza, dentre outros.

A primeira conferência internacional para o debate da questão climática foi a Assembleia Geral das Nações Unidas, tendo como resultado o tratado Convenção Quadro das Nações Unidas sobre Mudanças climáticas, em 1992, na ECO-92, a partir do qual se iniciaram encontros anuais entre os países signatários, denominados Conferências das Partes COPs. Dentre as COPs já realizadas, se destaca a COP 3, em Quioto, no Japão, que estabeleceu metas e prazos para redução e/ou limitação das emissões dos chamados Gases de Efeito Estufa -GEEs, e, como marco importante, o estabelecimento do Protocolo de Quioto (BUOTTE et al., 2020; ROCHA et al., 2017).

Visando o alcance das metas propostas no referido protocolo, foi proposto um instrumento de flexibilização 
denominado Mecanismo de Desenvolvimento Limpo (MDL), por meio do qual países desenvolvidos podem cumprir suas metas de redução de emissões via financiamento de projetos em países em desenvolvimento. Duas classes de projetos são elegíveis no âmbito do MDL: 1 . Redução de emissões via aumento da eficiência energética; 2. Remoção e estocagem de gases GEEs em sumidouros (como florestas, por exemplo).

Segundo Ontl et al. (2020) e Toochi (2018), as florestas são fundamentais na regulação da concentração de $\mathrm{CO}_{2}$ na atmosfera, tanto como emissões potenciais, em caso de degradação de áreas florestais, quanto sumidouro, por meio do sequestro de carbono atmosférico e sua conversão e armazenamento sob a forma de biomassa. Além disso, as florestas desempenham outras importantes funções ambientais, como manutenção da quantidade e da qualidade da água, regulação local e regional da temperatura, manutenção da resiliência ambiental e climática de áreas, regulação das precipitações e do teor de umidade atmosférico, dentre outros (AN et al., 2019; CARMO, 2016). Por isso, pela disponibilidade terras/áreas elegíveis e pelas condições naturais favoráveis de clima, Castro (2017) afirma que projetos MDL da modalidade florestal são a classe de mecanismo de flexibilização mais interessante para o Brasil, por meio dos quais, além dos serviços ambientais listados, é possível a geração de renda via comercialização de créditos de carbono.

A geração de créditos de carbono por meio de projetos MDL florestais pode ser empreendida via reflorestamento, florestamento ou restauração florestal (BERNAL et al., 2018), com espécies nativas ou exóticas. Em todos os casos, de acordo com Hou et al. (2019), é necessária uma avaliação do potencial de sequestro de carbono do projeto, o que pode ser feito conhecendo-se as espécies a serem utilizadas, a extensão de área disponível e o horizonte temporal do projeto, dentre outros aspectos técnicos.

O próprio Painel Intergovernamental sobre Mudanças Climáticas (IPCC) disponibiliza dados de referência para a elaboração de projetos, mas, segundo Bernal et al. (2018), por serem globais/regionais, não possuem acurácia válida para a heterogeneidade de condições ambientais ao longo do planeta, motivo pelo qual iniciativas específicas de prospecção e de estudo do potencial de sequestro são válidas e podem ser encontradas para um variado número de localizações geográficas e de especificidades técnicas.

Bernal et al. (2018) apresentaram uma melhoria em relação aos valores de referência do IPCC, avaliando as taxas de sequestro de $\mathrm{CO}_{2}$ via cenários variados de restauração florestal. Chazdon et al. (2016) estudaram cenários semelhantes, concluindo que os mesmos representam uma opção efetiva e de baixo custo, com grande potencial em áreas tropicais, sobretudo no Brasil.

Segundo Pugh et al. (2019), a identificação de cenários relevantes à restauração e a adoção de práticas de manejo nos mesmos pode maximizar tal potencial. Alvarenga e Carmo (2006) avaliaram o potencial em seringais implantados na zona da mata de Minas Gerais, concluindo que a espécie é altamente eficiente no sequestro de carbono atmosférico e com grande potencial de geração de benefícios sociais e econômicos a pequenos e médios produtores. Buotte et al. (2020) estudaram florestas no oeste dos Estados Unidos, identificando aquelas com maior potencial de sequestro de carbono e, por isso, prioritárias à preservação. Castro (2017) estimou o sequestro de carbono atmosférico em um projeto de restauração florestal em área de mata atlântica, para a compensação de emissões de $\mathrm{CO}_{2}$ advindas da implantação de uma central hidrelétrica.

Rodriguez (2015) também avaliou o lucro potencialmente gerado pela venda de créditos de carbono, porém, para reflorestamento ecológico de áreas de preservação permanente no município de São Luiz do Paraitinga, em São Paulo. Nesse caso, em 20 anos, estimou-se que seria gerada uma renda de US\$ 2.725.255,2. No caso de florestamento e/ou reflorestamento com espécies comerciais, o eucalipto se destaca, segundo Soares (2016), por apresentar elevada eficiência fotossintética e, consequentemente, elevado potencial de sequestro de carbono atmosférico. De acordo com Souza et al. (2019), computando o balanço de carbono em plantios da referida espécie para produção de madeira na região Norte de Minas Gerais, o potencial de sequestro seria da ordem de $172 \mathrm{Mg} \mathrm{ha}^{-1}$ de $\mathrm{CO}_{2}$.

Apesar de relativa disponibilidade de dados e estudos sobre o tema, ainda existe um vazio geográfico em termos de referências específicas acuradas, o que, segundo Chazdon et al. (2016) e Hou et al. (2019), mantém relevantes uma série de questões, como, por exemplo, sobre taxas locais de geração de biomassa, potencial de sequestro via biomassa e solos em florestamentos, potencial de sequestro via regeneração de áreas agrícolas e pastoris originalmente cobertas por florestas, atratividade financeira da conversão de áreas agrícolas em florestas, dentre outras.

No Brasil, o cenário não é diferente, e em regiões como no norte de Minas Gerais - com significativa atividade silvicultural, grandes extensões de áreas sob pastagens degradadas (BRASIL, 2015), áreas sob alta susceptibilidade à desertificação (MARQUES et al., 2017) e baixo índice de desenvolvimento humano (SANTOS; FONSECA, 2014) projetos MDL florestais podem representar uma contribuição, tanto ao meio ambiente, quanto à melhoria dos indicadores socioeconômicos da região.

Nesse sentido, o objetivo do presente trabalho foi avaliar, em caráter prospectivo preliminar, o potencial de sequestro de carbono atmosférico e de geração de créditos de carbono na porção mineira da bacia do Rio Pardo, na região norte do estado de Minas Gerais, a partir de cenários variados em projetos MDL florestais.

\section{MATERIAL E MÉTODOS}

A área de estudo abrangeu a porção da bacia do Rio Pardo, localizada na região norte do Estado de Minas Gerais (Figura 1), entre os paralelos $15^{\circ}$ e $16^{\circ}$, latitude sul e entre os meridianos $41^{\circ}$ e $43^{\circ}$, longitude oeste, compreendendo uma área de $12.700 \mathrm{~km}^{2}$, distribuída entre os municípios de Águas Vermelhas, Berizal, Curral de Dentro, Divisa Alegre, Indaiabira, Montezuma, Ninheira, Rio Pardo de Minas, Santo Antônio do Retiro, Santa Cruz de Salinas, São João do Paraíso, Taiobeiras e Vargem Grande do Rio Pardo (SILVA et al., 2017).

A região se encontra sob domínio de três grupos climáticos no sistema de classificação de Köppen: Aw, nas áreas de menor altitude e ao longo da drenagem principal, com estações chuvosas (verão) e secas (inverno) bem definidas; Cwa, nas maiores altitudes da porção sul da área, com verões quentes e chuvas concentradas entre os meses de novembro e fevereiro e; Cwb, nas maiores altitudes da porção norte, ao longo da Serra do Espinhaço, de verão moderadamente quente e com as menores temperaturas médias de inverno da microrregião (IGAM, 2013; SILVA et 
al., 2017). As temperaturas médias anuais variam entre 20 e $24^{\circ} \mathrm{C}$ e a precipitação média anual entre 700 e $1.000 \mathrm{~mm}$ (IGAM, 2013; SILVA et al., 2017). Os solos predominantes são os latossolos amarelos, os cambissolos e os neossolos litólicos, ocorrendo também, em áreas restritas, argissolos e neossolos flúvicos (IGAM, 2013). A vegetação natural regional é composta por fitofisionomias pertencentes aos biomas Caatinga, Cerrado e Mata Atlântica e formações de transição, compreendendo florestas subcaducifólias, caducifólias, caatinga hiperxerófila e formações rupestres (SILVA et al., 2017; IGAM, 2013).

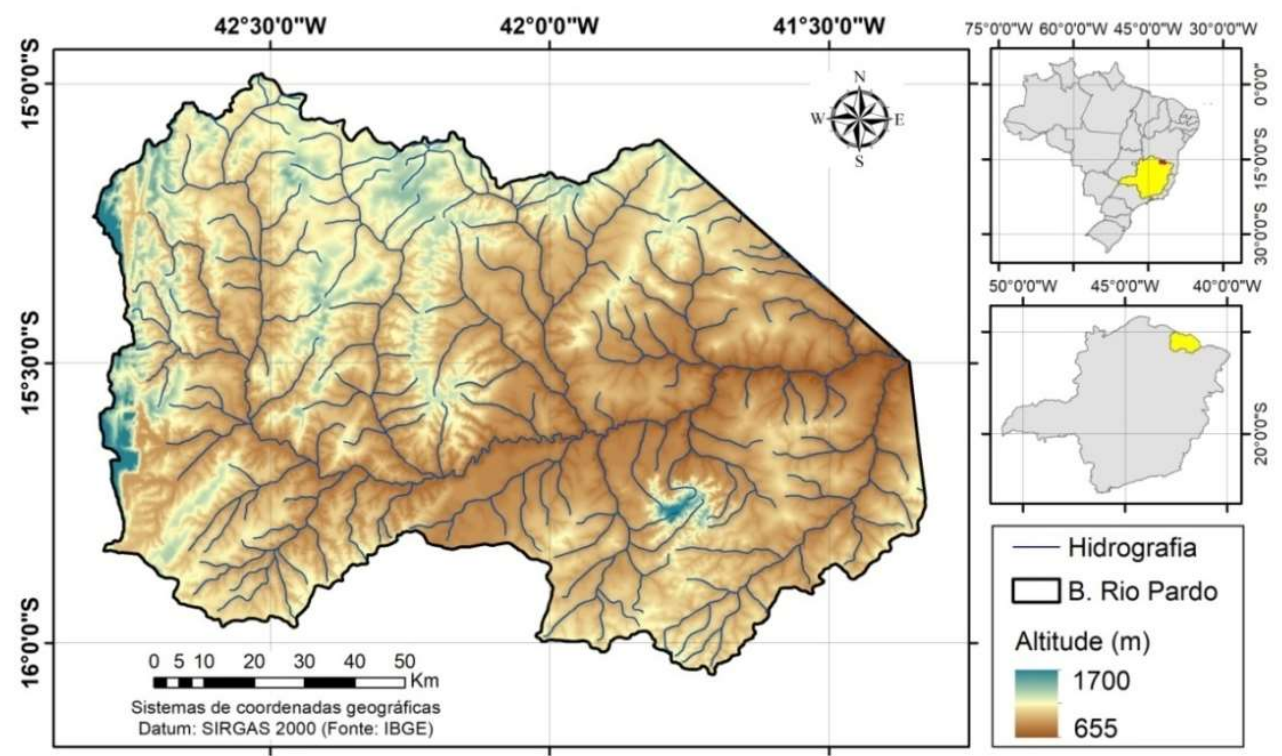

Figura 1. Localização da área de estudo.

Figure 1. Study area location.

Os materiais utilizados consistiram em dados da literatura e planos temáticos de informações cartográfico-espaciais. Os dados obtidos junto à literatura consistiram em valores de estoque de biomassa por espécie florestal ou fitofisionomia, enquanto que as informações geográficas foram obtidos junto a bancos de dados gratuitos diversos, compreendendo imageamentos orbitais multiespectrais Landsat 5 e 8 (Serviço Geológico dos Estados Unidos - USGS https://earthexplorer.usgs.gov), cenas de modelos digitais de elevação da missão SRTM com resolução espacial de $30 \mathrm{~m}$ (Serviço Geológico dos Estados Unidos - USGS) e mapas vetoriais da rede de drenagem (Agência Nacional de Águas ANA - https://www.gov.br/ana/pt-br), de biomas (Instituto Brasileiro de Geografia e Estatística - IBGE https://www.ibge.gov.br/) e limites político-administrativos (Instituto Brasileiro de Geografia e Estatística - IBGE). Para o processamento das informações geográficas foram utilizados os softwares IDRISI, versão Andes gratuita, e QGIS Desktop 2.18.23.

A metodologia consistiu, resumidamente, no mapeamento das áreas aptas à implantação de projetos em Mecanismo de Desenvolvimento Limpo - MDL florestais na porção mineira da bacia do Rio Pardo e na simulação de sequestro e geração de créditos de carbono para cenários de regeneração florestal e reflorestamento com espécies de eucalipto. As etapas percorridas encontram-se detalhadas nas próximas seções.

\subsection{Mapeamento das áreas aptas à implantação de projetos MDL florestais}

O mapeamento das áreas aptas à implantação de projetos MDL florestais na área de estudo se deu a partir do seguinte raciocínio: (i) para projetos de restauração florestal, as áreas aptas são aquelas que atendem ao critério de elegibilidade estabelecido pelo Protocolo de Quioto, segundo o qual deverão obrigatoriamente possuir área mínima contígua de $10.000 \mathrm{~m}^{2}$ e estarem desflorestadas desde 31 de dezembro de 1989 - evitando a ocorrência de desmatamento intencional da vegetação natural com o objetivo de geração e comercialização de créditos de carbono; (ii) para projetos de reflorestamento com espécies de eucalipto, as áreas devem, além de atender aos critérios do Protocolo de Quioto, serem favoráveis à implantação do referido gênero e estarem fora de limites de Áreas de Preservação Permanente - APPs.

\subsection{1. Áreas elegíveis e aptas à implantação de projetos $M D L$ de restauração florestal}

Foram utilizadas imagens de satélite Landsat 5 TM dos anos 1990, 1994, 2003, 2009, e Landsat 8 TM para os anos 2014 e 2017, obtidas gratuitamente junto ao Serviço Geológico dos Estados Unidos - USGS, dando-se preferência por imagens de épocas secas e com menos cobertura de nuvens. Devido à extensão geográfica da área de estudos, foram confeccionados mosaicos - um para cada banda utilizada (vermelho e infravermelho próximo) - sendo necessárias quatro cenas Landsat para a cobertura total da área. Em seguida, os mosaicos foram recortados tendo-se por molde o contorno vetorial da bacia em questão.

O mapeamento das áreas elegíveis se procedeu a partir da identificação e análise multitemporal das coberturas florestais e não florestais, utilizando-se o Índice de Vegetação da Diferença Normalizada - NDVI. O procedimento se iniciou com a geração de uma imagem NDVI para o ano inicial da série histórica - 1990 - sobre a qual se aplicou o limiar de 0,275 para se gerar uma "máscara", via função "reclassificação", de áreas não florestadas à referida data. Esse limiar corresponde ao valor máximo do NDVI para áreas não cobertas por vegetação de porte florestal, baseando-se em Santos et al. (2018). Em seguida, efetuou-se a interseção espacial entre a máscara e as imagens NDVI dos 
demais anos da série histórica, detectando-se assim eventuais pixels/áreas com valores do índice superiores ao limiar de referência para áreas não florestadas; possivelmente resultantes de regeneração florestal ou reflorestamentos não pleiteantes. Ao final do procedimento, dentre as áreas não florestadas que se mantiveram sob tal condição ao longo da série histórica analisada, foram selecionadas aquelas com área contígua superior à $10.000 \mathrm{~m}^{2}$.

\subsection{2. Áreas elegíveis e aptas à implantação de projetos MDL de reflorestamento}

Nessa etapa, os procedimentos compreenderam o mapeamento das APPs, tratadas por hora como uma restrição a projetos de reflorestamento com eucalipto e um zoneamento agroecológico simplificado, para o mapeamento das áreas favoráveis ao desenvolvimento da referida espécie, neste caso considerando-se uma variedade híbrida Eucalyptus urophylla $\mathrm{x}$ Eucalyptus grandis.

Para o mapeamento das APPs de topo de morro, primeiramente, foi realizado o mapeamento dos morros geográficos a partir da inversão do relevo, subtraindo-se o Modelo Digital de Elevação (MDE) original de um valor constante maior do que a maior altitude da área de estudos. Como resultado, os topos de morro se transformam em depressões e as suas bases se transformam na bacia de contribuição das mesmas. A delimitação de tais "bacias" permitiu a identificação dos morros, dentre os quais, por meio de função zonal, foram selecionados apenas os com altura superior a $100 \mathrm{~m}$, obedecendo ao novo código florestal. Para cada morro ora identificado, foi calculada a sua declividade utilizando-se a sua altura e a distância entre o ponto de base mais próximo e o ponto de topo, selecionando-se apenas aqueles com declividade superior a $25^{\circ}$. Por fim, para cada morro selecionado, foi calculada a altitude correspondente a dois terços de sua altura total por meio da "calculadora raster". As APPs de topo de morro foram então mapeadas identificando-se os pixels do MDE original com altitude superior à altitude correspondente a dois terços de cada morro.

As APPs de cursos d'água foram geradas aplicando-se um buffer de $30 \mathrm{~m}$ sobre a rede de drenagem gerada a partir do MDE original. Utilizando-se a mesma rede de drenagem, foram identificados os pontos de início de todos os canais de primeira ordem, aplicando-se sobre tais pontos um buffer de $50 \mathrm{~m}$, para o mapeamento das APPs de nascentes de cursos d'água. Por fim, as APPs referentes a áreas com declividade igual ou superior a $45^{\circ}$ foram mapeadas via reclassificação do mapa de declividade gerada, via função slope, a partir do MDE original. Todas as classes de APPs, mapeadas seguindo o proposto pelo Código Florestal, foram unidas em um mapa único, tratado como restrição no procedimento seguinte de mapeamento das áreas favoráveis ao desenvolvimento de espécies de eucalipto.

Para o zoneamento agroecológico do eucalipto na área de estudos, foi adotado um procedimento simplificado do tipo booleano, por meio do qual as áreas somente são consideradas favoráveis se cada fator analisado favorecer integralmente a espécie em questão. Os fatores considerados foram classe do solo (classes favoráveis: cambissolos, latossolos e podzólicos), textura do solo (texturas favoráveis: arenosa, argilosa, média/argilosa e média) e disponibilidade hídrica do solo (favorável: armazenamento médio maior ou igual à demanda hídrica da cultura, de $100 \mathrm{~mm} / \mathrm{ano})$. Os fatores foram mapeados via seleção por atributo, exportados como novos mapas, convertidos para o formato raster, reclassificados em valores finais "zero" (áreas não favoráveis) e "um" (áreas favoráveis), multiplicados entre si e pelo mapa de restrições por APPs, para a geração do mapa de áreas favoráveis ao reflorestamento com eucalipto. Por fim, este mapa foi interseccionado espacialmente com o mapa de áreas elegíveis, gerando o mapa final de áreas aptas e elegíveis, segundo os critérios do Protocolo de Quioto, para a implantação de projetos MDL de reflorestamento.

\subsection{Cenários de sequestro e de créditos de carbono}

Os cenários de sequestro e geração de créditos de carbono propostos consistiram em: (i) restauração florestal com espécies nativas nas áreas sob domínio dos três biomas da bacia (caatinga, cerrado e mata atlântica) e; (ii) reflorestamento com espécies de eucalipto nas áreas favoráveis e elegíveis.

Nos cenários de regeneração, os estoques de $\mathrm{CO}_{2}$ foram estimados tendo-se por base valores médios de biomassa de carbono por bioma, de acordo com os valores de estoque de $\mathrm{CO}_{2}$ equivalente $\left(\mathrm{CO}_{2 \text { eq }}\right)$ observados no Inventário Florestal do Estado de Minas Gerais. Para a Caatinga, foi adotada a média dos estoques de $\mathrm{CO}_{2 \mathrm{eq}}$ observados para Floresta Estacional Decidual entre os estágios médio e avançado de regeneração (SCOLFORO et al., 2008a). Para o Cerrado, a média entre as formações stricto sensu e campo cerrado (SCOLFORO et al., 2008b), e para a Mata Atlântica, a média entre Floresta Estacional Semidecidual e Floresta Estacional Decidual (SCOLFORO et al., 2008c). A média foi utilizada devido à ausência de referências sobre a proporção de área de cada fitofisionomia dentro dos biomas.

As estimativas de sequestro de carbono para reflorestamento com eucalipto foram realizadas levando-se em consideração a rotação técnica de 6 anos para um híbrido de Eucalyptus urophylla $\mathrm{x}$ Eucalyptus grandis com produtividade referente ao nível tecnológico de intermediário a alto $(28,003$ $\mathrm{m}^{3} \cdot \mathrm{ha}^{-1}$.ano $\mathrm{O}^{-1}$ ) - valor médio de produtividade para região Alto Rio Pardo/MG, de acordo com resultados não publicados de 20 inventários realizados pelo IFNMG Campus Salinas em plantios na região. A quantidade de carbono estocada foi estimada conforme a Equação 1, de acordo com Scolforo (2008d), em que a densidade básica média da madeira utilizada no cálculo da biomassa foi de $515 \mathrm{~kg} / \mathrm{m}^{3}$ e a percentagem de carbono considerada foi de $50 \%$. Para o cálculo do estoque de $\mathrm{CO}_{2}$ foi utilizada a equação do dióxido de carbono equivalente (Equação 2), conforme Scolforo (2008d).

$$
\mathrm{C}=\mathrm{V}_{\mathrm{c} / \mathrm{c}} \cdot \mathrm{D} \cdot \mathrm{C}(\%)
$$

em que: $\mathrm{C}=$ quantidade de carbono estocado $\left(\mathrm{Mg}^{2} \mathrm{ha}^{-1} \cdot \mathrm{ano}^{-1}\right)$; $\mathrm{V}_{\mathrm{c} / \mathrm{c}}=$ volume total com casca $\left(\mathrm{m}^{3} \cdot \mathrm{ha}^{-1} \cdot \mathrm{ano}^{-1}\right) ; \mathrm{D}=$ densidade básica da madeira; $\mathrm{C}(\%)=$ teor de carbono na madeira.

$$
\mathrm{CO}_{2 \mathrm{eq}}=\mathrm{C} \cdot \frac{44}{12}
$$

em que: $\mathrm{CO}_{2 \mathrm{eq}}=$ dióxido de carbono equivalente $\left(\mathrm{Mg} \cdot \mathrm{ha}^{-1} \cdot \mathrm{ano}^{-1}\right) ; \mathrm{C}$ $=$ quantidade de carbono estocado; $44=$ massa atômica do $\mathrm{CO}_{2} ; 12$ $=$ massa atômica do C.

\section{RESULTADOS}

Foram mapeados 992,2 ha de áreas elegíveis na parte da bacia sob bioma Caatinga, 27.027,4 ha em áreas sob bioma Cerrado e 78.991,4 ha de áreas sob bioma Mata Atlântica, 
totalizando 107.011 ha elegíveis à implantação de projetos MDL de restauração florestal. As distribuições espaciais das referidas áreas encontram-se representadas nas Figuras 2a, 2b e 2c, respectivamente. Para projetos MDL de reflorestamento com eucalipto, foram mapeados 76.010,1 ha elegíveis e aptos, com distribuição espacial ao longo de toda a bacia, como representado na Figura 2d.

A partir dos valores médios de $\mathrm{CO}_{2}$ estocado por bioma, foram obtidos valores médios de sequestro de $\mathrm{CO}_{2}$ equivalente de $67,71 \mathrm{Mg} \mathrm{ha}^{-1}$ para formações de Caatinga, $35,85 \mathrm{Mg} \mathrm{ha}^{-1}$ para formações de Cerrado e de 116,21 Mg ha 1 para formações de Mata Atlântica. Aplicando-se esses valores às áreas elegíveis por bioma, foi calculado o potencial de sequestro de carbono atmosférico - por bioma e total para a bacia - via projetos MDL de restauração florestal, apresentado na Tabela 1.

Para reflorestamentos com eucalipto, tendo como referência um híbrido de Eucalyptus sp, o valor médio de $\mathrm{CO}_{2}$ equivalente ou de sequestro de $\mathrm{CO}_{2}$ foi igual a $26,44 \mathrm{Mg}$ ha ${ }^{1}$ ano $^{-1}$. O valor total de CO2 equivalente sequestrado em seis anos, caso todo o potencial da bacia seja explorado com esse tipo de projeto de MDL, seria de 12.058.012,27 Mg, que equivale à quantidade expressiva de 2.009.668,71 Mg.ano-1 de $\mathrm{CO}_{2}$ removido da atmosfera, conforme apresentado na Tabela 2.
Tabela 1. Potencial de sequestro de $\mathrm{CO}_{2}$ através de projetos MDL de restauração florestal bacia do rio Pardo, Minas Gerais

Table 1. $\mathrm{CO}_{2}$ sequestration potential through $\mathrm{CDM}$ forest restoration projects in the Pardo River Basin, Minas Gerais.

\begin{tabular}{lccc}
\hline Bioma & Área (ha) & $\begin{array}{c}\mathrm{CO}_{2 \mathrm{eq}} \\
\left(\mathrm{Mg} \mathrm{ha}^{-1}\right)\end{array}$ & $\begin{array}{c}\text { Total de } \mathrm{CO}_{2 \mathrm{eq}} \\
\text { removido }(\mathrm{Mg})\end{array}$ \\
\hline Caatinga & 992,22 & 67,71 & $67.178,36$ \\
Cerrado & $27.027,37$ & 35,85 & $968.931,21$ \\
Mata Atlântica & $78.991,40$ & 116,21 & $9.179 .709,08$ \\
\hline Total & $107.010,99$ & $95,47^{*}$ & $10.215 .818,65$ \\
\hline
\end{tabular}

* Média ponderada de $\mathrm{CO}_{2 \text { eq }}$ em função da área dos biomas.

Tabela 2. Potencial de sequestro de $\mathrm{CO}_{2}$ via projetos MDL de reflorestamento com eucalipto na bacia do rio Pardo, Minas Gerais. Table 2. $\mathrm{CO}_{2}$ sequestration potential via $\mathrm{CDM}$ reforestation projects with eucalyptus in the Pardo River basin, Minas Gerais.

\begin{tabular}{lccc}
\hline $\begin{array}{l}\text { Tipo de } \\
\text { Vegetação }\end{array}$ & Área (ha) & $\begin{array}{c}\mathrm{CO}_{2 \mathrm{e}} \\
\left(\mathrm{Mg} \mathrm{ha}^{-1}\right)\end{array}$ & $\begin{array}{c}\mathrm{CO}_{2 \mathrm{eq}} \text { Total } \\
(\mathrm{Mg})\end{array}$ \\
\hline $\begin{array}{l}\text { Reflorestamento } \\
\text { com Eucalipto }\end{array}$ & $76.010,09$ & 158,64 & $12.058 .012,27$ \\
\hline
\end{tabular}

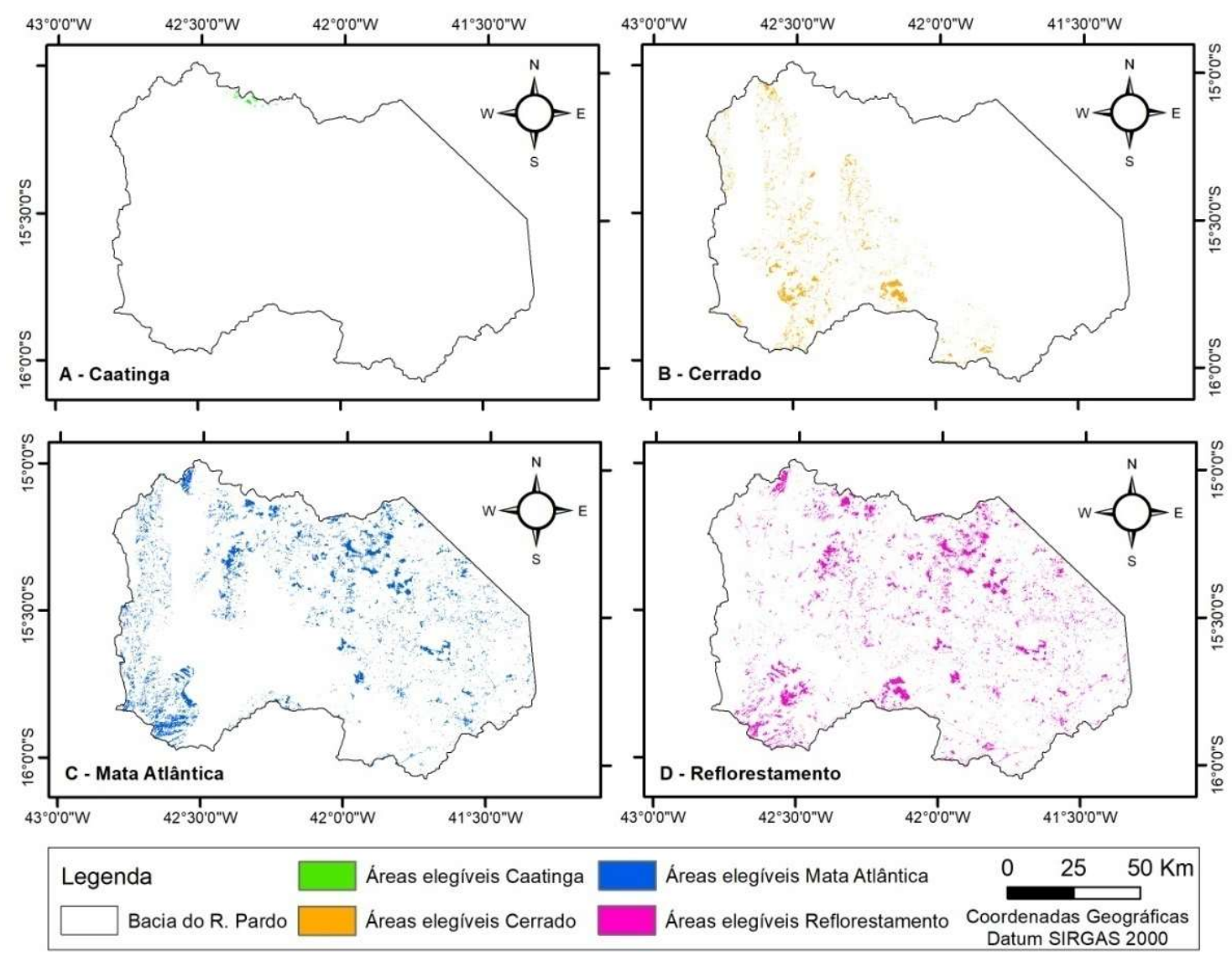

Figura 2. Distribuição espacial de áreas elegíveis e aptas a projetos MDL de restauração florestal e reflorestamento. Figure 2. Spatial distribution of eligible and suitable áreas for CDM forest restoration and reforestation projects.

\section{DISCUSSÃO}

Segundo Gomes et al. (2017), devido às variações entre formações vegetais pertencentes ao bioma Caatinga, não é possível se estabelecer um valor final único de estoque de biomassa por unidade de área para o mesmo, podendo variar entre 2 e $166 \mathrm{Mg} \mathrm{ha}^{-1}$ de biomassa - No entanto, o sequestro potencial de $\mathrm{CO}_{2 \text { eq }}$ estimado para a porção da área de estudo sob o bioma em questão $\left(67,71 \mathrm{Mg} \mathrm{ha}^{-1}\right)$ se encontra dentro da referida faixa de variação, entre 3 e $243 \mathrm{Mg} \mathrm{ha}^{-1}$. Para o cerrado, o potencial de sequestro médio $\left(35,85 \mathrm{Mg} \mathrm{ha}^{-1}\right)$ foi inferior aos valores médios predominantes (55 $\left.\mathrm{Mg} \mathrm{ha}^{-1}\right)$ estimados via inventário florestal e sensoriamento remoto 
por Santos et al. (2018), para a mesma bacia. No entanto, como se atribuiu às formações de cerrado da área um estágio intermediário de regeneração, espera-se que o potencial de sequestro de $\mathrm{CO}_{2 \text { eq }}$ via restauração florestal para esse bioma na área de estudos seja superior ao estimado. No caso das áreas sob bioma de Mata Atlântica, o potencial de sequestro situou-se abaixo do estimado, para o mesmo bioma, em Castro (2017). Entretanto, a área estudada pelo autor se encontra próxima ao litoral do estado de São Paulo e, por isso, apresenta naturalmente produtividade primária superior às formações florestais do bioma em questão na região norte de Minas Gerais.

As diferenças entre os potenciais estimados de sequestro e valores da literatura não invalidam o estudo nem os trabalhos consultados, pois corroboram o afirmado em Bernal et al. (2018), Chazdon et al. (2016) e Hou et al. (2019), sobre a importância da realização de estudos locais diante das incertezas associadas a valores regionais de referência, da variabilidade espacial e da variabilidade fitofisionômica dentro de um mesmo bioma. Além disso, há possibilidade de as estimativas obtidas para a área de estudos serem válidas apenas para os locais amostrados, pois como se trata de um ambiente típico de transição entre três biomas diferentes, as fitofisionomias da bacia, por vezes, podem apresentar estrutura e características híbridas.

Quanto ao valor potencial de retorno financeiro com a comercialização dos créditos de carbono, não é possível a estimativa de montantes exatos, uma vez que o preço da tonelada de $\mathrm{CO}_{2}$ equivalente é altamente variável, oscilando em função do comportamento do mercado diante de oferta e demanda, podendo variar entre 1 e 139 US\$ por megagrama de carbono (Carbon Pricing And Carbon Credits: Definition, Examples And History, 2020). No entanto, de acordo com o projeto Partnership for Market Readiness Brazil (https://www.gov.br/fazenda/pt-br/orgaos/spe/pmrbrasil), o valor médio dos créditos comercializados no Brasil é de aproximadamente $10 \mathrm{US} \$ \mathrm{Mg}^{-1}$. A esse valor, projetos MDL de restauração florestal, na presente área de estudo, poderiam gerar cerca de 102 milhões de dólares, em um período de 20 anos (5,1 milhões de dólares por ano), caso todo o potencial da área de estudos fosse explorado.

Para reflorestamento com eucalipto, o potencial de sequestro de $\mathrm{CO}_{2}$, de $26,44 \mathrm{Mg} \mathrm{ha}^{-1} \mathrm{ano}^{-1}$, foi praticamente igual ao apresentado em Souza et al. (2019), de 26,76 Mg ha ${ }^{1}$ ano $^{-1}$; baseado em dados de inventários realizados por empresas de silvicultura também localizadas na região norte de Minas Gerais. Por isso, e pelo fato de que há maior disponibilidade de dados sobre a espécie e controle sobre as condições nos plantios, a estimativa para a área de estudos foi considerada plausível.

Segundo Araujo (2017), no ano de 2017, o crédito de carbono foi comercializado ao preço de US\$ 5,20 na BMF Bovespa, US\$10,00 na Bolsa de Montreal e de US\$13,00 na Bolsa de Los Angeles. Considerando-se que os créditos de carbono gerados com o reflorestamento de toda a área elegível e apta à cultura em questão, para o ciclo de 6 anos, sem considerar a taxa de juros, fossem comercializados nas referidas bolsas de valores, o montante obtido com a comercialização dos créditos seria de US\$ 62.701.663,8; US\$ 120.580.122,7; US\$ 156.754.159,5, respectivamente. Tais valores poderão ser maiores em um futuro próximo, pois, segundo CPLC (2017), os preços deveriam ter variado, no mínimo, entre US\$40-80 $\mathrm{Mg}^{-1} \mathrm{CO}_{2 \mathrm{eq}}$ em 2020 e estarem entre US\$50-100 $\mathrm{Mg}^{-1} \mathrm{CO}_{2 \mathrm{eq}}$ em 2030.
Os totais potenciais estimados de sequestro e geração de créditos de carbono para os dois cenários propostos de projetos MDL florestais - restauração e reflorestamento com eucalipto - foram razoavelmente próximos. No entanto, para o alcance do mesmo patamar, projetos de restauração florestal demandariam em mais de três vezes o tempo requerido por reflorestamento, fazendo com que, à primeira vista, esta alternativa seja preferível em relação à primeira.

Segundo Soares (2016), o eucalipto apresenta maior eficiência na conversão de $\mathrm{CO}_{2}$ em biomassa, comparado às espécies típicas das fitofisionomias naturais da área de estudo, e a geração de créditos de carbono e renda poderia ocorrer também em um segundo momento, com a destinação da madeira produzida ao final do ciclo cultural adotado.

Por outro lado, projetos de restauração com espécies do próprio bioma podem gerar maiores benefícios ambientais e, na impossibilidade de financiamentos que compensem o baixo rendimento, em créditos de carbono, por ano, podem ser uma alternativa atrativa de incentivo à recuperação de áreas de preservação permanente, como indicam Castro (2017), Rodriguez (2015), Velasco; Higuchi (2009) e Martins (2004). Nesse sentido, um cenário misto, com reflorestamento comercial nas áreas elegíveis e favoráveis ao eucalipto juntamente a restauração florestal com espécies nativas em áreas de preservação permanente seria o ideal, uma vez que, segundo Oliveira et al. (2013), dentre os cerca de 45.000 ha mapeados de APPs, há indícios de que uma parcela considerável esteja degradada.

\section{CONCLUSÕES}

A bacia do Rio Pardo, em Minas Gerais, apresenta considerável potencial de sequestro de carbono atmosférico e de geração de renda via comercialização de créditos de carbono, com retornos financeiros potenciais, para os horizontes de projeto considerados no presente trabalho, da mesma ordem de grandeza do produto interno bruto (PIB) total de boa parte dos municípios da bacia, segundo o IBGE.

Apesar do cenário "reflorestamento" ter sido mais vantajoso, financeiramente, um cenário misto, composto por reflorestamento em áreas aptas/elegíveis e por restauração florestal em APPs, foi considerado o ideal para a áreas de estudos.

A metodologia adotada mostrou-se viável à avaliação prospectiva, mas deve ser aperfeiçoada com a utilização de parâmetros locais de biomassa por bioma, fitofisionomias e atividade silvicultural.

\section{AGRADECIMENTOS}

À Fundação de Amparo à Pesquisa do Estado de Minas Gerais (FAPEMIG), pelo apoio financeiro.

\section{REFERÊNCIAS}

ALVARENGA, A. P.; CAMO, C. A. F. S. (Eds.). Sequestro de carbono: quantificação em seringais de cultivo e na vegetação natural. Viçosa: UFV; Rio de Janeiro, Embrapa Solos, 2006. 338p.Disponível em: http://www.infoteca.cnptia.embrapa.br/infoteca/handl e/doc/338847. Acesso: 17 de Ago. 2020.

AN, H.; SEOK, H. D.; LEE, S.; CHOI, J. Forest management practice for enhancing carbon sequestration in national forests of Korea. Forest Science and Technology, v. 15, n. 2, p. 80-91, 2019. DOI: https://doi.org/10.1080/21580103.2019.1596843 
ARAUJO, G. J. F. Análise energética, ambiental e econômica de biodigestores de circulação interna $\mathrm{e}$ concentradores de vinhaça para geração de eletricidade, fertilizantes e créditos de carbono em diferentes cenários econômicos. 2017. 316f. Tese (Doutorado em Ciências) - Universidade de São Paulo, Ribeirão Preto, 2017.

BERNAL, B.; MURRAY, L. T.; PEARSON, T. R. H. Global carbon dioxide removal rates from forest landscape restoration activities. Carbon Balance Management, v. 13, n. 1, p. 13-22, 2018. DOI: https://doi.org/10.1186/s13021-018-0110-8

BRASIL. Ministério da Agricultura, Pecuária e Abastecimento - Superintendência Federal de Agricultura de Minas Gerais. Estado da arte das pastagens em Minas Gerais. Belo Horizonte: MAPA, 2015. 207p.

BUOTTE, P. C.; LAW, B. E.; RIPPLE, W. J.; BERNER, T. L. Carbon sequestration and biodiversity co-benefits of preserving forests in the western United States. Ecological Applications, v. 30, n. 2, p. 1-11, 2020. DOI: https://doi.org/10.1002/eap.2039

Carbon Pricing And Carbon Credits: Definition, Examples And History. Youmatter, 21, fev. 2020. Disponível em: https://youmatter.world/en/definition

/definitions-carbon-price-carbon-credit/. Acesso em: 26 jan. 2021.

CARMO, F. C. A. Balanço da emissão de gases carbônicos nas operações florestais e sequestro de carbono em florestas plantadas no Espírito Santo. 2016. 68f. Tese (Doutorado em Ciências Florestais) Centro de Ciências Agrárias, Universidade Federal do Espírito Santo, Jerônimo Monteiro, 2016.

CASTRO, A. G. Estimativa de sequestro de carbono florestal para restauração ecológica devido às emissões de $\mathrm{CO}_{2}$ na instalação de uma central geradora hidrelétrica - CGH. 2017. 140f. Tese (Doutorado em Engenharia Mecânica) - Universidade Estadual Paulista, Faculdade de Engenharia de Guaratinguetá, Guaratinguetá, 2017.

CHAZDON, R. L; BROADBENT, E. N.; ROZENDAAL, D. M. A.; et al. Carbon sequestration potential of secondgrowth forest regeneration in the Latin American tropics. Science Advances, v. 2, n. 5, p. 1-10, 2016. DOI: 10.1126/sciadv.1501639

CARBON PRICING LEADERSHIP COALITION (CPLC). Report of the High-Level Commission on Carbon Prices. 2017. Washington, DC: World Bank. 69p. Disponível em: https://www.carbonpricingleader ship.org/s/CarbonPricing_FullReport.pdf. Acesso em: 29 fev. 2021.

GOMES, V. P.; GALVÍNCIO, J. D.; SILVA, J. F.; FERREIRA, P. S.; LACERDA, A. C. O papel do bioma Caatinga no sequestro de carbono no contexto das mudanças climáticas. In: NÓBREGA. R. S.; SILVA, A. S. da; SILVA, A. K. de C.; COSTA, A. M. M.; DANTAS, A. M. da S.; LIRA, D. V. de; MELO, E. E. de; BORGES, G. F. D. de S.; SILVA, G. A. da; SOUZA, L. M. da S.; SENA, L. M. F. de; OLIVEIRA, T. N. de; ROSÁRIO, T. N. da S.; HOLANDA, T. F. de (Orgs.). Reflexões sobre o semiárido: obra do encontro do pensamento geográfico. 1 ed. Belém-PA: Itacaiúnas, 2017, v. 1, p. 276-280.

HOU, G.; DELANG, C.O.; LU, X.; OLSCHEWSKI, R. Valuing Carbon Sequestration to Finance Afforestation
Projects in China. Forests, v. 10, n. 754, p. 2-20, 2019. DOI: https://doi.org/10.3390/f10090754

IGAM_Instituto Mineiro de Gestão das Águas. Fase I Diagnóstico integrado do meio físico-biótico, antrópico e das disponibilidades e demandas hídricas - Plano diretor de recursos hídricos da bacia hidrográfica dos afluentes mineiros do rio Pardo. Belo Horizonte: IGAM, 2013. 728p.

MARQUES, M. V. A.; MOREIRA, A. A.; NERY, C. V. M. Diagnóstico da desertificação na região Norte de Minas Gerais por meio de técnicas de geoprocessamento. Boletim de Geografia, Maringá, v. 35, n. 2, p. 99-116, 2017. https://doi.org/10.4025/bolgeogr.v35i2.27361

MARTINS, O. S. Determinação do potencial de sequestro de carbono na recuperação dematas ciliares na região de São Carlos - SP. 2004. 136f. Tese (Doutorado em Ecologia e Recursos Naturais) Universidade Federal de São Carlos, São Carlos, 2004.

OLIVEIRA, B. M.; MARTINS, R. S. F.; SANTOS, R. M. Mapeamento preliminar de conflitos de uso da terra na bacia do Rio Pardo - MG. In: Simpósio Brasileiro de Sensoriamento Remoto (SBSR), XVI., 2013, Foz do Iguaçu. Anais... São José dos Campos: INPE, 2013. p. 6246-6251. Disponível em: http://marte2.sid.inpe.br/rep/dpi.inpe.br/marte2/2013 /05.29.01.12.58. Acesso em: 18 set. 2020.

ONTL, T. A.; JANOWIAK, M. K.; SWANSTON, C. W.; DALEY, J.; HANDLER, S.; CORNETT, M.; HAGENBUCH, S.; HANDRICK, C.; MCCARTHYL, PATCH, N. Forest management for carbon sequestration and climate adaptation. Journal of Forestry, v. 118, n. 1, p. 86-101, 2020. DOI: https://doi.org/10.1093/jofore/fvz062

PUGH, T. M.; LINDESKOG, M.; SMITH, B.; POULTER, B.; ARNETH, A.; HAVERD, V.; CALLE, L. Role of forest regrowth in global carbon sink dynamics. Proceedings of the National Academy of Sciences, v. 116, n. 10, p. 4382-4387, 2019. DOI: https://doi.org/10.1073/pnas.1810512116

ROCHA, W. D. O.; PEREIRA, A. M.; DA SILVA, A. E.; FRAGA, J. A. Estimativa de biomassa vegetal e sequestro de carbono no Parque Natural Municipal Flor do Ipê,Várzea Grande, MT. Multitemas, Campo Grande, v. 22, n. 51, p. 179-195, 2017. DOI: https://doi.org/10.20435/multi.v22i51.1284

RODRÍGUEZ, C. R. M. Estimativa do potencial sequestro de carbono em áreas de preservação permanente de cursos d'água e topos de morros mediante reflorestamento com espécies nativas no município de São Luiz do Paraitinga. 2015. 120 f. Dissertação (Mestrado em Meteorologia) - Instituto Nacional de Pesquisas Espaciais - INPE, São José dos Campos, 2015.

SANTOS, M. R.; FONSECA, G. S. Índice de Desenvolvimento Humano Municipal (IDHM) em 2000 e 2010 da microrregião de Salinas - Norte de Minas. Revista Cerrados, Brasília, v. 12, n. 01, p. 225-248, 2014. SANTOS, R. M.; LIMA, V. O. B.; VICENTE, M. R.; CAMARA, T. M.; MENDES, C. C. A.; SILVA, D. M.; BARBOSA, G. S. Relação entre resposta espectral, biomassa e estoque de carbono em ocorrências de cerrado na porção mineira da bacia do rio Pardo: estudo preliminar. In: TÚLIO, L. (Org.). Aplicações e 
Princípios do Sensoriamento Remoto. 1ed. Ponta Grossa: Atena Editora, 2018, v. 1, p. 199-208. Disponível em: https://www.finersistemas.com/atenaeditora/ index.php/admin/api/artigoPDF/3221. Acesso em: 27 jul. 2020.

SCOLFORO, J. R. et al.Volumetria, peso de matéria seca e carbono para o domínio da caatinga. In: MELLO, J. M.; SCOLFORO, J. R.; CARVALHO, L. M. T. (Eds.). Inventário Florestal de Minas Gerais: Floresta Estacional Decidual - Florística, Estrutura, Similaridade, Distribuição Diamétrica e de Altura, Volumetria, Tendências de Crescimento e Manejo Florestal. Lavras: UFLA, 2008a. cap. 8, p.157-208.

SCOLFORO, J. R. et al.Volumetria, peso de matéria seca e carbono. In: SCOLFORO, J. R.; MELLO, J. M.; OLIVEIRA, A. D. (Eds.). Inventário Florestal de Minas Gerais: Cerrado - Florística, Estrutura, Diversidade, Similaridade, Distribuição Diamétrica e de Altura, Volumetria, Tendências de Crescimento e Áreas Aptas para Manejo Florestal. Lavras: UFLA, 2008b. cap. 8, p. 361-438.

SCOLFORO, J. R. et al. Volumetria, peso de matéria seca e carbono para o domínio atlântico em Minas Gerais. In: SCOLFORO, J. R.; MELLO, J. M.; SILVA, C. P. de C. (Eds.). Inventário Florestal de Minas Gerais: Floresta Estacional Semidecidual e Ombrófila - Florística, Estrutura, Similaridade, Distribuição Diamétrica e de Altura, Volumetria, Tendências de Crescimento e Manejo Florestal. Lavras: UFLA, 2008c. cap. 8, p.461630.

SCOLFORO, J. R. et al. Tendências da produção em volume, peso de matéria seca e carbono dos reflorestamentos em Minas Gerais. In: SCOLFORO, J. R.; CARVALHO, L. M. T.; OLIVEIRA, A. D. (Eds.). Inventário Florestal de Minas Gerais: Monitoramento dos reflorestamentos e tendências da produção em volume, peso de matéria seca e carbono. Lavras: UFLA, 2008d. cap. 2, p.93-149.

SILVA, R. J.; CHIAPETTI, R. J. N.; ARAÚJO, G. S. Atlas físico da bacia hidrográfica do rio Pardo para uso escolar. Revista de Ensino de Geografia, Uberlândia, v. 8, n. 14, p. 67-93, 2017.

SOARES, G. M. Estoque de carbono em plantas jovens de Eucalyptus e Corymbia em diferentes densidades de plantio. 2016. 65 f. Dissertação (Mestrado- Programa de Pós-graduação em Biocombustíveis) - Universidade Federal dos Vales do Jequitinhonha e Mucuri, Diamantina, 2016.

SOUZA, C. L.; SCHETTINO, S.; SILVA, D. D.; GUIMARÃES, N. V. Balanço de carbono do processo de produção de madeira de reflorestamento no norte de Minas Gerais. Caderno de Ciências Agrárias, Montes Claros, v. 11, p. 1-8, 2019. DOI: https://doi.org/10.35699/2447-6218.2019.15160

TOOCHI, E. C. Carbon sequestration: how much can forestry sequester $\mathrm{CO}_{2}$ ? Forestry Research and Engineering: International Journal,v. 2, n. 3, p. 148 150, 2018.2 DOI: https://doi.org/10.15406/freij.2018.02.00040.

VELASCO, G. D. N.; HIGUCHI, N. Estimativa de sequestro de carbono em mata ciliar: projeto POMAR, São Paulo (SP). Ambiência, Guarapuava, v. 5, n.1, p. 135-141, 2009 